\section{El subsistema de la prescripción en el derecho administrativo}

\author{
The subsystem of the prescription in administrative law
}

\begin{abstract}
RESUMEN
Una figura jurídica de notable evolución es la prescripción, que se sustenta en todas legislaciones del mundo con variables en cuanto al tiempo; la misma que ha sido necesaria legislarla, empezando en las bases administrativas cuyo principio ha sido el de solicitar la prescripción en el denominado: a petición de parte y no por decisión de oficio. En este contexto, la figura de la prescripción se convierte en un principio constitucional, cuyo análisis es necesario ventilarse en diferentes disciplinas jurídicas que se dictan en universidades; no solo en las facultades de derecho, sino también en otras que en sus planes curriculares involucran disciplinas considerando el principio de prescripción. Tal figura no es reciente, sino se remonta desde de los primeros lustros de la época romana y se invoca bajo dos alcances; uno de prescripción adquisitiva y otro de prescripción extintiva o liberatoria.. Palabras claves: Prescripción; a petición de parte; decisión de oficio.
\end{abstract}

\begin{abstract}
A legal figure of notable evolution is that of prescription, which is based on all laws of the world with variables in terms of time, the same that has been necessary starting from the administrative bases whose principle has been to request the prescription in the so-called : At the request of a party and not by decision of its own motion; In this context the figure of the prescription becomes a constitutional principle, whose analysis is necessary to ventilate in the different legal disciplines that are dictated in university courses, not only in the faculties of law, but also in others that in their curricular plans involve Disciplines without leaving aside the principle of prescription, this figure is not recent, but dates back to the early lusters of Roman times and is invoked under two scopes, one of prescription prescription and another of extinctive or liberatory prescription.
\end{abstract}

Keywords: Prescription; at the request of a party; interested party; decision ex officio.

\section{Percy Alberto Catacora Santisteban}

pcatacoras@unmsm.edu.pe

Universidad Nacional Mayor de San Marcos, Facultad de Ciencias Administrativas

(c) Los autores. Este artículo es publicado por Gestión en el Tercer Milenio de la Facultad de Ciencias Administrativas de la Universidad Nacional Mayor de San Marcos. Este es un artículo de acceso abierto, distribuido bajo los términos de la licencia Creative Commons Atribucion - No Comercia_Compartir Igual 4.0 Internacional. (http://creativecommons.org/licenses/by-nc-sa/4.0/) que permite el uso no comercial, distribución y reproducción en cualquier medio, siempre que la obra original sea debidamente citada. 


\section{INTRODUCCIÓN}

El objeto de la investigación se sustenta en que la figura de la prescripción, que es de interés, en principio, para todos aquellos que tienen relación patrimonial reflejada en la relación directa entre el titular propietarioy su inmueble. Pero, con el devenir del tiempo, se desnaturaliza dicha relación cuando se torna indirecta, y esto tiene que ver básicamente, con el interés de la posesión constante y permanentedel patrimonio. Esto se da por la sencilla razón de supervisar tal relación, mediante diferentes actosjurídicos como es el mantenimiento del inmueble, el pago de obligaciones municipales, el crédito con garantía hipotecaria, el anticresis, el comodato, la relación contractual del fideicomiso, el arrendamiento, etc. La problemática se suscita cuando esa constante supervisión se distancia con el abandono del bien, surgiendo el aprovechamiento de terceras personas que se introducen mediante la invasión, cuando se quedan como cuidantes o porque se convierten en ocupantes precarios. Tales situaciones tienen su raíz en la prescripción adquisitiva del patrimonio inmobiliario, que ha ido evolucionando y acomodándose a nuevos hechos cósmicos y sociales. En ese sentido, la prescripción no la encontramos únicamente en la parte sustantiva del derecho; sino también en la parte adjetiva o procedimental, lo que comprobamos con la nueva normatividad del derecho administrativo, especialmente en el llamado proceso administrativo. Esto nos obliga hacer una remembranza de la época en que se gesta la prescripción, la misma que en tiempos de Roma se denominaba usucapión, palabra que viene del latín usucapio, de usus, uso o posesión, y capere, tomar o adquirir. La usucapión es la adquisición de un derecho o de una propiedad a través de su ejercicio en las condiciones y plazos previsto por la ley. Esta también conocida como prescripción adquisitiva, es el modo de acceder a la propiedad de una cosa mediante la posesión continua de los derechos reales durante el tiempo que establece la legislación.

Otro de los elementos que hay que tener en claro respecto de la usacapión, es que esta tiene carácter retroactivo. Y se considera que, una vez transcurrido el plazo, la adquisición del derecho se produjo en el instante en el que dio comienzo a aquella figura, hasta el vencimiento del último día del plazo.

El decurso prescriptorio, se computa todo el tiempo transcurrido, sin interrupción, comprendiéndose los días hábiles y los inhábiles; los que convergen en el plazo cumplido. La existencia de la usucapión puede justificarse mediante dos teorías: la teoría objetiva y subjetiva.

La teoría objetiva sostiene que el fundamento de la usucapión se encuentra en otorgar seguridad a las relaciones jurídicas al consolidar las titularidades aparentes. Esta teoría, por lo tanto, busca mantener el statu quo de la posesión.

La teoría subjetiva, en cambio, justifica la usucapión a partir del abandono o la renuncia al derecho real por parte del titular; en vista que este no ejercita ninguna acción de defensa frente a la posesión de otratercera persona. El problema de esta posturase suscita cuando el titular demuestra que la voluntad de renuncia es inexistente, la usucapión queda inmediatamente invalidada.

Es interesante establecer la existencia de dos variables claramente diferenciadas de usucapión. Así, por un lado, nos encontramos con la llamada ordinaria, que es aquella que se identifica por requerir un justo título por el transcurso del tiempo establecido por la ley y también el uso de buena fe.

Es importante tener claro, que ese mencionado título tiene que ser válido $\mathrm{y}$ verdadero, y además, tiene que probarse y no presumirse.

Por otro lado, está la extraordinaria, que no requiere ninguno de los dos elementos mencionados; es decir, no necesita la invocación del título ni la buena fe.

Existe la figura contraria de la prescripción adquisitiva o usucapión, cual es la prescripción extintiva o liberatoria; la que puede definirse como el modo de extinguirse los derechos y las acciones por el mero hecho de no dar adecuadas señales de vida durante el plazo fijado por la ley. Así se pone de relieve que junto con el transcurso del tiempo, lo característico de la prescripción extintiva es la inacción del titular 
del derecho durante toda la extensión de aquel; es lo que se ha denominado con acierto, como el silencio de la relación jurídica.

La Enciclopedia Jurídica OMEBA, consigna en forma muy precisa, lo siguiente: "En el nacimiento, vida y extinción de las relaciones jurídicas, el tiempo es factor que cabe considerar en planorelevante. Al transponer el umbral de la mayoría de edad, cesanlas incapacidades que la minoría engendraba; la creación intelectual que la Carta Magna protege con énfasis, atribuye sus prerrogativas, por el término que le acuerde la ley. Si bien en solitarias ocasiones, el tiempo es capaz de producir consecuencias jurídicas sin necesidad que se le sumen otras circunstancias, la mayoría de las veces requiere de ellas para provocar modificaciones jurídicas. La prescripción utiliza el tiempo para producir sus consecuencias, pero le agrega otros ingredientes que denotan sus particularidades. Si el titular de determinados derechos reales, deja de usarlos durante cierto tiempo su derecho real queda extinguido".

El jurista Fernando Vidal Ramírez, comenta en su Libro sobre Prescripción Extintiva y Caducidad, lo siguiente: "En una noción genérica la prescripción se puede entender como un medio o modo por el cual, en ciertas condiciones, el decurso deltiempo modifica sustancialmente una relación jurídica.

La prescripción, en esta noción genérica, según la explica Enneccerus, es el nacimiento y la terminación o desvirtuación de derechos en virtud de su ejercicio continuado o desu no ejercicio continuado y; en consecuencia, distingue la prescripción adquisitiva - que nosotros preferimos llamar usucupativa o simplemente usucapión - de la prescripción extintiva. Advierte el tratadista alemán que la prescripción no se configura de un modo uniforme para todas las relaciones jurídicas y que, por tanto, hay que prescindir de una doctrina general de la prescripción; aunque algunas de sus manifestaciones concretas se repitan en las distintas clases de prescripción".

La prescripción es un medio por el cual, con el transcurso del tiempo y bajo determinadas condiciones, se libra de una obligación.
Según el comentario del tradicional jurista italiano Nicolás Coviello, en su Tratado de Doctrina General del Derecho Civil, considera que: "Varias razones suelen aducirse para justificar la prescripción extintiva: el interés social de que las relaciones jurídicas no queden por largo tiempo inciertas; la presunción de que el que descuida el ejercicio del propio derecho, no tiene voluntad de conservarlo; la utilidad de castigar la negligencia; la acción del tiempo que todo lo destruye. Todas estas razones pueden aceptarseya que no se excluyen recíprocamente, sino que convergen todas a justificar cumplidamente la prescripción".

Al remitirnos al Código Civil en su Libro de la Prescripción Extintiva, se resalta lo que establece el Art. $1992^{\circ}$ : "El juez no puede fundar sus fallos en la prescripción si no ha sido invocada". Consideramos que la petición de invocar se refiere al derecho del litigante demandado, obligado o emplazado, - sin referirnos al denunciado involucrado en la vía penal. Tal fundamento concuerda con los alcances de la normatividad de derecho administrativo, como lo que establece la Ley $\mathrm{N}^{\circ}$ 27444 - Ley de Procedimiento Administrativo General, sobre el particular. En la aplicación del proceso administrativo disciplinario, en esencia permite la invocación de la prescripción extintiva o liberatoria de la obligación a pedido de parte y no de oficio; es decir, no es por decisión de la autoridad administrativa. Sin embargo, las autoridades municipales, que comprueban que ha habido omisión o morosidad en el pago de las obligaciones tributarias, como la del impuesto predial y arbitrios, transcurrido más de cuatro años ya no ejecutan la cobranza, por haber prescrito. Tal criterio se rescata de la fuente tributaria, (nos referimos a los alcances del Código Tributario), en esa forma tácitamente la autoridad administrativa está aplicando la prescripción extintiva de oficio. Este análisis, contrasta con una última sentencia del Tribunal Constitucional, con motivo de la acción de cobro de bonos por la deuda agraria que interpuso el representante del Colegio de Ingenieros de Lima contra el Estado. La cobranza data de más de diez años, generada con motivo de las expropiaciones por la Ley de Reforma Agraria en tiempo del Gobierno de Velasco Alvarado. Si aplica el Estado la prescripción extintiva la cobranza se habría extinguido por razones 
del tiempo transcurrido previsto en el Código Civil de 1936 y en el actual de 1984; pero lo anecdótico es que uno de los vocales del Tribunal Constitucional, Dr. Vergara Gotelli, en forma singular, planteó la solución de la controversia mediante la decisión de oficio aplicando la prescripción extintiva. En ese sentido, no tuvo en cuenta lo establecido en el Art. 1992 del Código Civil, en el caso que la prescripción se aplica a pedido de parte y no de oficio.

La problemática de la prescripción, en el procedimiento disciplinario sancionador, es de especial importancia; toda vez que en muchos procesos administrativos ventilados en las comisiones encargadas sobre la materia, han emitido resoluciones diferentes creándose una polarización administrativa, las que han dado lugar a apelaciones con el propósito de agotar la vía administrativa. Es por eso que el Tribunal del Servicio Civil, bajo el contexto de la Ley 30057, convocó al pleno administrativo, - al igual como acontece en el Poder Judicial - para sentar las bases que sirvieran de interpretación rectora extensivo a todas las entidades públicas $\mathrm{y}$, consiguientemente, para las comisiones encargadas de los procesos disciplinarios. Los acuerdos adoptados por el pleno supremo administrativo tienen la categoría jurisprudencial para que los órganos administrativos los adoptenpara uniformizar sus decisiones.

Distinta situación es lo que acontece en el Derecho Penal, donde prima el principio de favorecer al reo, por el beneficio del transcurso del tiempo en forma ordinaria o extraordinariay que por excepción de oficio aplica la autoridad jurisdiccional sin que la parte interesada la haya invocado.

Según el jurista argentino, Vera Barros, 0. (2008) Señala en su tratado de La Prescripción Penal en el Código Penal: "Si la prescripción tiene por efectoimpedir que se produzca elcastigo, no puede obedecer a otra cosa que a la extinción del derecho a castigar que tiene el Estado. Lo que quizá perturbe un poco la comprensión del problema son los efectos procesales que genera la prescripción, pero ello no es más una consecuencia de la extinción del poder punitivo del Estado en el caso concreto".

\section{OBJETIVO}

El objetivo fundamental de esta investigación está referido al proceso disciplinario administrativo, al que con motivo del sometimiento, el administrado sea servidor o funcionario público, que ha sido denunciado y en el séquito del proceso disciplinario, tiene derecho - cuando así lo amerite - de invocar la prescripción administrativa liberatoria; pero dentro de la competencia única de su accionar omisivo o lesivo en contra de los intereses de la entidad, sin perjuicio de que el hecho tenga consecuencias de responsabilidad penal, pasible de ser denunciado ante la autoridad competente.

En nuestro medio, el órgano especializado que sienta las bases delalcance de la prescripción en materia de procesos disciplinarios, es el Tribunal del Servicio Civil; el mismo que para definir la naturaleza jurídica de la prescripción, en el marco del Decreto Legislativo $\mathrm{N}^{\circ} 1023$, ha tomado en cuenta las aportaciones de juristas, cuyas opiniones son importantes en materia de Derecho Administrativo, y especialmente en el tema de prescripción. Así tenemos: Para Marcial Rubio Correa, "la prescripción es una institución jurídica según la cual, el transcurso de un determinado tiempo extingue la acción que el sujeto tiene para exigir un derecho ante los tribunales".

Para Zegarra Valdivia, al analizar la prescripción en el ámbito administrativo, sancionador, afirma que esta es una limitación al ejercicio tardío del derecho en beneficio de la seguridad; por ello, se acoge en aquellos supuestos, en los que la Administración, por inactividad, deja de transcurrir el plazo máximo legal para ejercitar su derecho a exigir o corregir las conductas ilícitas administrativas o interrumpe el procedimiento de persecución de la falta durante un lapso de tiempo"

Para Morón Urbina: "Los motivos lógicos que sirven de fundamento al instituto de la prescripción administrativa no son diversos de la prescripción en general. Afirma que cuando pasa largo tiempo sin que se haya sancionado una infracción, el tiempo modifica las circunstancias concurrentes y desaparece la adecuación entre el hecho y la sanción principal". 
Por su parte, el Tribunal Constitucional ha afirmado que la figura jurídica de la prescripción no puede constituir, en ningún caso, un mecanismo para proteger jurídicamente la impunidad de las faltas que pudieran cometer los funcionarios o servidores públicos, puesto que esta institución del derecho administrativo sancionador no solo tiene la función de proteger al administrado frente a la actuación sancionadora de la Administración; sino también, la de preservar que, dentro de un plazo razonable, los funcionarios competentes cumplan, bajo responsabilidad, con ejercer el poder de sanción de la administración contra quienes pueden ser pasibles de un procedimiento administrativo disciplinario ".

La Constitución, en el artículo $139^{\circ}$ inc.1.3. establece que la prescripción produce los efectos de cosa juzgada, esto significa que si el proceso administrativo disciplinario se ha cerrado o concluido por razones de la aplicación de la figura jurídica de prescripción, el motivo que ha dado lugar al proceso disciplinario no puede ser removido ni causa antecedente para un proceso distinto; siendo una garantía de carácter jurisdiccional. Es por eso que el Tribunal Constitucional ha interpretado y extendido su aplicación al proceso administrativo, como una garantía al debido proceso y a la tutela administrativa efectiva.

El Tribunal Constitucional, en su potestad de interpretar la ley y como órgano de control de la Constitución, según reza del artículo $201^{\circ}$ de dicho texto, en Materia Penal, ha establecido la calificación de aquellos hechos que constituyen agravios a los derechos humanos como de esa humanidad; determinando que los actores no pueden acogerse a la figura de la prescripción, siendo los hechos de tal naturaleza que son imprescriptibles, como es el delito del denominado caso Tarata dentro del contexto de delitos de terrorismo y tráfico ilícito de drogas, que se atribuye a los cabecillas de Sendero Luminoso. El tribunal referido al Colegiado. "A" de la Sala Penal Nacional, ha establecido, en su resolución, que el plazo extraordinario de prescripción no puede aplicarse, en vista que los titulares han sido sentenciados a cadena perpetua.
Lo anotado en los anteriores párrafos, demuestra la diferencia sustancial entre el campo penal y el administrativo; en este, no puede considerarse la imprescriptibilidad de la falta administrativa.

Es interesante resaltar que con motivo de la Ley 30057, llamada Ley Servir, el Tribunal del ServicioCivilha aclarado mediante la Resolución de Sala Plena $N^{\circ}$ 001-2016-SERVIR/TSC de fecha16 de agosto de 2016, los alcances y la aplicación técnica de la figura de la prescripción liberatoria en el proceso disciplinario administrativo; sentando el criterios precedente vinculante de cumplimiento obligatorio, en la siguiente forma:

1. El plazo de prescripción para el inicio del procedimiento administrativo disciplinario, de conformidad con el artículo $97^{\circ}$ del Reglamento, establece que la facultad para determinar la existencia de faltas disciplinarias e iniciar el procedimiento disciplinario prescribe conforme a lo previsto en elartículo $94^{\circ}$ de la Ley, a los tres años calendario de cometida la falta; salvo que, durante ese periodo, la oficina de recursos humanos de la entidad, o la que haga sus veces, hubiera tomado conocimiento de la misma. En este supuesto, la prescripción operará un año calendario después de esa toma de conocimiento por parte de dicha oficina, siempre que no hubiera ocurrido el plazo anterior.

2. Para elcaso delos ex servidores civiles, elplazo de prescripción es de dosaños calendario; computados desde que la entidad conoció de la comisión de la infracción.

La prescripción será declarada por el titular de la entidad de oficio o a pedido de parte, sin perjuicio de la responsabilidad administrativa correspondiente

3. En el caso de la falta continuada, para el cómputo del plazo, se entiende que la comisión de la falta se produce con el último acto que suponga la comisión de la misma falta. 
Eso demuestra la generalizaciónde que la autoridad administrativa está aplicando de oficio la figura de la prescripción.

No estamos en la teoría de la interrupción de la prescripción, como sucede en otras disciplinas como las previstas en el Derecho Civiltampoco en la figura de la prescripción taxativa, donde el transcurso del tiempo es fatal para el acreedor, como es el caso del artículo $1274^{\circ}$ del Código Civil que establece que "La acción para recuperar lo indebidamente pagado prescribe a los cinco años de efectuado el pago" Esto demuestra quela prescripción extintiva se aplica en forma vertical, sin discusión en contrario y no admite interrupción en el tiempo; en vista que la ley se ha establecido en el sentido que la prescripción se cuenta a partir del dinero que el acreedor haya materializado la entrega del dinero a favor del prestatario, el mismo que se convierte en deudor. Esto podría suceder cuando el pagador ha entregado un monto de dinero en exceso o por error ha pagado dinero por encima de lo normal. Si la cobranza es oportuna, se produce una justificación y si sucede inercia para el cobro puede peligrar la devolución, por el principio de la prescripción.

Sobre el particular, nos permitimos presentar la ilustración gráfica sobre la prescripción común.

\section{Gráfico de prescripciones comunes}

\begin{tabular}{|c|c|}
\hline PRESCRIPCION ADQUISITIVA & Inmuebles máximo 10 años \\
\hline ON EXTIN & acción personal 10 años \\
\hline PRESCRIPCION TAXATIVA & pago indebido \\
\hline
\end{tabular}

Gráfico de prescripción en el proceso administrativo disciplinario

\section{Supuesto $\mathrm{N}^{\circ} 01$}

Hechos 15.3.15

15.3.15

tres ( 3 ) años desde la comisión de la falta

Un (01) año desde que RRHH a la que haga sus veces toma conocimiento de la falta

10.3.18

Entidad que conoce la falta
10.3.19

opera la prescripción

\section{Supuesto $\mathrm{N}^{\circ} 02$}

Hechos 15.3.15

15.3.18

tres ( 03 ) años desde la comisión de la falta
1.5 .15

Entidad que conoce la falta
Un (01) año desde que RRHH o la que haga sus veces toma conocimiento de la falta

15.5.16

opera la prescripción
NOTA.- El anterior gráfico se sustenta en lo establecido en el artículo $94^{\circ}$ de la Ley 30057- Ley del Servicio Civil y en el artículos $97^{\circ}$ del Decreto Supremo N ${ }^{\circ}$ 040-2014-PCM que es el Reglamento de dicha Ley

\section{MÉTODO}

El tema de investigación que comentamos, ha sido objeto de una exploración relacionada con expedientes relativos a procesos disciplinarios , con motivo de la plena aplicación de la Ley 27444 - Ley de Procedimiento Administrativo General en concordancia con el D.L. 276 y el proceso contencioso administrativo: El primero en la jurisdicción netamente administrativa y el segundo en la vía jurisdiccional. Tal exploración y análisis la hacemos en la vigencia de la Ley 30057 - Ley del Servicio Civil, que sin haber sido derogadas las anteriores, siguen siendo aplicables y son acogidaspor las interpretaciones del Tribunal del Servicio Civil, al emitir las correspondientes ejecutorias y jurisprudencia.

El estudio se ha hecho, mediante las comparaciones de expedientes sobre hechos parecidos y casos precedentes, - consideramos como método el comparativo - determinándose que en la mayor cantidad de los expedientes ventilados, el mayor porcentaje han sido materia de revocatoria; otros han sido declarados nulos y otros han sido confirmados en cuanto a las sanciones emitidas por el órgano inferior y otro porcentaje han sido objeto de absolución, sin perjuicio de considerar que el menor porcentaje de los casos se ha beneficiado conla excepción de prescripción .

¿Quiénes son las personas denunciantes? La mayor parte de los procesos disciplinarios proceden de los órganos de control interno institucional, los otros casos proceden 
de denuncias de los propios órganos administrativos de relación funcional y por último por denuncias de personas interesadas, que consideran han sido afectados sus derechos.

Antes, los procesos administrativos disciplinarios estaban sujetos a un sistema reglamentario para cada nivel de los servidores o funcionarios. A la fecha, si bien es cierto que existen las resoluciones que determinan la conformación de los órganos, disciplinarios, más puntual es la aplicación de la Ley 30057 y su reglamento.

Dentro de ese análisis comparativo, podemos considerar que los procesos administrativos disciplinarios, en el campo netamente de las entidades administrativas, cumplen en la mayor parte con los términos; sin embargo, nos encontramos con la encrucijada de que los procesos se dilatan mucho tiempo en la vía jurisdiccional, al extremos que podríamos decir que esa morosidad se torna agobiantes para la parte administrada.

\section{RESULTADOS}

Los procesos administrativos contra servidores y funcionarios de las entidades públicas relacionadas con el ámbito de aplicación a que se refiere el artículo $1^{\circ}$ de la Ley 27444 , nos llevan a considerar los siguientes resultados:

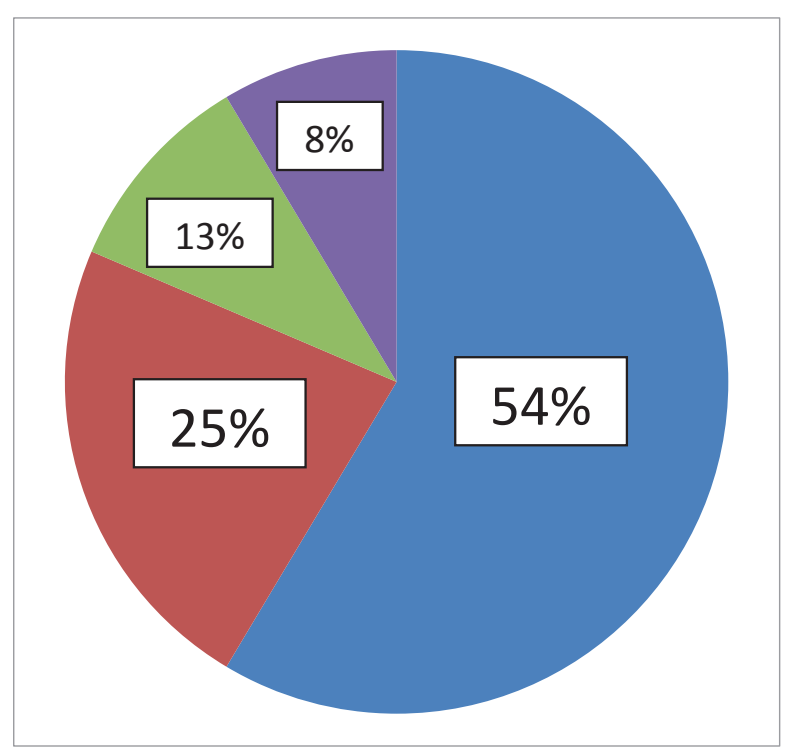

AZUL : $54 \%$ DE PROCESOS REVOCADOS ROJO : $25 \%$ DE PROCESOS CONFIRMADOS VERDE : $13 \%$ DE PROCESOS ANULADOS MORADO: $8 \%$ DE PROCESOS PRESCRITOS
Los procesos anulados, sean por decisión de los propias autoridades administrativas que tienen a su cargo el trámite procedimental o por la autoridad superior, en este caso el Tribunal del Servicio Civil que es el que analiza técnicamente, el cumplimiento de las disposiciones administrativas, devuelve los expedientes para que el órgano inferior haga las correspondientes subsanaciones. Así como; el proceso sea arreglado a Ley, igualmente pueden estar sujetos a la nulidad de los actos administrativos; los procesos que se han acogido al principio de prescripción extintiva o liberatoria.

\section{DISCUSIÓN}

Cumplimos con hacer los contrastes entre los antecedentes de los procesos administrativos disciplinarios, con el sistema administrativo que actualmente rige en aplicación de la normatividad promulgada a partir del 2013, el reglamento de la Ley y las resoluciones del Tribunal del Servicio Civil , las directivas del mismo y los acuerdos adoptados en el pleno administrativo . Llegamos a concluir que la filosofía que sirve de base al sistema administrativo y que se confirma con los principiosadministrativoscontenidos en la Ley 27444 - Ley de Procedimiento Administrativo General y la normatividad de la Ley 30057 Ley del Servicio Civil y fundamentalmente los criterios establecidos por los miembros del Tribunal del Servicio Civil, demuestran acertados fallos técnicos que pueden servir de modelos para la casuística.

Nosotros sabemos que en las universidades, especialmente en las facultades de derecho, se dictan el curso de Derecho Administrativo y dentro de sus unidades académicas comprende el proceso administrativo disciplinario que es de interés en pre grado y especialmente en las unidades de post grado, toda vez que el mayor número de estudiantes prestan servicios en el sector público y/o entidades independientes y autónomas del Estado, esto demuestra que el estudio, análisis e investigación sobre la materia, es importante para mejorar el quehacer del trámite administrativo y mejorar la actuación de los servidores en la toma de decisiones. 
Las teorías administrativas han ido mejorando, demostrándose que nos encontramos en proceso devolución; sin dejar de considerar las pautas que nos puedan brindar los jueces y salascontencioso administrativos y el Tribunal Constitucional, en vista que la impugnaciónpodría ventilarse en procesos constitucionales de amparo bajolacompetencia del mencionado Tribunal.

Peseaquesehanpresentadoimpugnaciones por parte de servidores de algunos organismos sectoriales, se aprecia que las decisiones se van acomodando a los hechos de carácter social; comprobándose que la normatividad vigente va acomodándose a las necesidades de los servidores del Estado, en vista que sus conclusiones en materia de procedimientos administrativos disciplinariosdemuestran toda una especialización.

El enfoque principal, en lo que estamos de acuerdo, es que las autoridades administrativas encargadas del trámite deprocesos deben tener mucho cuidado en calificar y tipificar el hecho incurrido, a mérito de una descripción muy cuidadosa. Para evitar ser pasibles de nulidades, queremos decir que en materia administrativa, al igual que la judicial, las resoluciones deben ser debidamente motivadas tal como lo prevé la Constitución.

Con la normatividad anterior, se hacían las críticas y reclamos; en la actualidad, la nueva normatividad concuerda con las expectativas, tanto de las autoridades administrativas como la de los administrados.

\section{CONCLUSIONES}

1. Todavía existen deficiencias de interpretación entre el hecho incurrido y el derecho aplicado en los procesos administrativos disciplinarios.

2. Pese a que se han emitido normas como la Ley del Servicio Civil, su reglamento, directivas, acuerdo del pleno administrativo y sentencias que ponen fin a las controversias, se requiere mayor concientización por parte de las autoridades administrativas para tramitar con eficiencia los procesos administrativos disciplinarios.
3. La normatividad jurídica emitida últimamente a partir del año 2013, ha venido aclarando la posición decisiva por parte de la autoridad administrativa que tiene a su cargo el trámite de los procesos disciplinarios.

4. Se ha comprobado, que el Tribunal del Servicio Civil, es un organismo cada vez más especializado, sobre todo en materia de procesos administrativos disciplinarios.

5. Se ha demostrado la conveniencia que, el Tribunal del Servicio Civil, continuamente convoque a plenos administrativos, con intervención de especialistas en derecho administrativo, con el objeto de superar cualquier deficiencia procedimental y sustantiva, para mejorar cada vez la especialidad en materia de procesos administrativos disciplinarios.

6. Es muy plausible que se tenga en cuenta el debido proceso y la tutela administrativa, para garantía del proceso administrativo, a fin de evita la nulidad de los procesos.

7. Es muy plausible que las resoluciones tanto de los órganos administrativos de primera instancia, así como el de última instancia, tengan en cuenta como principio que sus resoluciones sean debidamente motivadas.

8. Es conveniente la capacitación continua de las autoridades responsables de llevar el trámite los procesos administrativos disciplinarios, capacitación que debe estar a cargo de especialistas, si es posible a cargo de miembros del Tribunal del Servicio Civil.

\section{REFERENCIAS BIBLIOGRÁFICAS}

Coviello, Nicolas (1960) Doctrina General del Derecho Civil; Méjico, Unión Tipográfica Editorial Hispano - Americana

OMEBA (1979) Enciclopedia Jurídica Omeba - Tomo XXII; Buenos Aires - Argentina, Industria Gráfica del Libro S.R.L. 
Vera Barrios, Oscar N. (2007) La Prescripción Penal en el Código Penal; Córdova- Argentina, LERNER Editores S.R.L.

Vidal Ramírez, Fernando (2002) Prescripción Extintiva y Caducidad; Lima, Gaceta Jurídica

Colección Constitucional Peruana (2005) Primera Edición Oficial, Diario El Peruano

Código Civil (1984) Edición Oficial 1998

Ley $N^{\circ} 27444$ Ley de Procedimiento Administrativo General (2001) Edición Oficial El Peruano

Ley N ${ }^{\circ} 30057$ Ley del Servicio Civil (2013 - Edición Oficial El Peruano del 4 de julio 2013

D.S. $N^{\circ}$ 040-2014-PCM - reglamento de la Ley 30057 El Peruano del 13 de junio 2014

Resolución N 001-2016 SERVIR/TSC del Tribunal del Servicio Civil El Peruano 12 setiembre 2016i 
Percy Alberto Catacora Santisteban 